\title{
Competencies for effective public health nutrition practice: a developing consensus
}

\author{
Roger Hughes* \\ Nutrition Unit, School of Health Science, Griffith University, Gold Coast, Queensland 4217, Australia
}

Submitted 13 August 2003: Accepted 6 November 2003

\begin{abstract}
Objectives: To assess the level of consensus amongst an international panel of public health nutrition leaders regarding the essential competencies required for effective public health nutrition practice.

Design: A modified Delphi study involving three rounds of questionnaires.

Subjects: A panel of 20 public health nutrition experts from seven countries in the European Union, the USA and Australia.

Results: Expert panellists completed three rounds of the study relating to competencies. A literature review conducted as a prelude to the expert panel survey identified common competency units from the fields of public health, health promotion, nutrition and dietetics, and health education. These were categorised into seven competency areas including analytical, socio-cultural and political, public health service, communication, management and leadership, nutrition science and professional competency categories. There was strong initial agreement $(\geq 90 \%$ of panellists at Round 1) that developing internationally recognised competencies for public health nutrition specialists was a priority. Twenty-six of an initial listing of 52 competency units were rated as essential competencies by $\geq 80 \%$ of the panellists after Round 1. Iteration rounds resulted in the addition of five extra competency units suggested by panellists after Round 1 and an increase by 13 in the number of competencies rated as essential to consensus levels. From a total of 57 competency units rated after the final survey round, 41 competency units were rated as essential competencies by $\geq 80 \%$ of the panellists (consensus), with 21 of these unanimously rated as essential competencies.

Conclusions: There is strong international agreement amongst public health nutrition leaders in Europe, the USA and Australia about a range of competencies required for effective public health nutrition practice. Essential competency units identified can be used to develop and review competency standards for public health nutrition.
\end{abstract}

Keywords Public health nutrition Competencies Consensus development
Competencies, competency standards and credentialling are all variations on a world-wide movement within the education, training and professional sectors. This movement is based on the premise that people need to be taught and be assessed on the knowledge, skills and attitudes required for effective performance in the workforce. This is supported by an argument that competency-based training enhances the education sector's responsiveness to the economy and produces reliable outcomes ${ }^{1}$. This approach has been applied in the field of public health nutrition in the USA ${ }^{2,3}$ and more recently in Europe by the Nutrition Society, which has established a registration and credentialling system for public health nutritionists based on agreed competency expectations ${ }^{4,5}$.

There is now a considerable literature debating the merits and limitations of the competencies movement ${ }^{1,6-10}$. This debate has been mostly related to the broader training and education environment rather than specifically applied to nutrition or public health. Advocates of the competency-based training approach see it as a countervailing force against education producing people who know but cannot do, whereas critics argue that an overemphasis on competencies can mean that people only become skilled in relation to a particular occupation ${ }^{11}$. Despite this debate, competencies are a widely accepted tool for workforce development in public health.

Public health workforce development scholarship over the last few years has emphasised the importance of developing a competent public health workforce as a precursor to increasing societal capacity to protect and promote the public's health ${ }^{12-16}$. As a result, there has been an emphasis on developing competencies standards to provide the architecture for workforce development in public health ${ }^{17,18}$, preventive medicine ${ }^{15,19}$, health promotion $^{20,21}$ and health education fields ${ }^{22}$. It has also been 
of interest to public health nutrition scholars ${ }^{3,4,23-25}$. Many of the competencies identified in this literature are similar, with considerable overlap across fields. Most of this scholarship has been profession-, discipline- or countryspecific.

The underlying premise of this study is that the competencies required for effective public health nutrition practice are largely consistent across countries and settings, with differences relating to the mix of competencies required to effectively address local problems in socio-cultural and other contexts. If this premise is true, it means that workforce development for public health nutrition can be based on a consensus set of competencies that are transferable between countries. One way of testing this premise is to assess levels of agreement about the competencies needed for effective practice in different countries. This study aimed to assess the level of agreement amongst public health nutrition leaders in different countries about competencies considered essential for effective public health nutrition practice.

\section{Method}

This study involved a modified Delphi study investigating and developing consensus relating to public health nutrition definitions (previously reported ${ }^{26}$ ), workforce composition, core functions and competencies (study schematic depicted in Fig. 1). Round 2 of the three-round study focused on assessing agreement about competency needs for different workforce tiers; the results from this round will be reported elsewhere. Data from questions relating to competencies and consensus developed between Rounds 1 and 3 are reported here.

\section{Consensus method}

The Delphi technique has been used widely in health research within the fields of technology assessment, education and training (including competency development) and in developing practice areas, and as a method has been systematically reviewed ${ }^{27}$. The aim is to determine the extent to which experts agree about a given issue, and the technique can be applied to both the measurement and development of consensus ${ }^{28}$. The Delphi technique consists of a series of intensive questionnaire rounds amongst a panel of experts interspersed with controlled opinion and feedback. In the first round, expert panellists are presented with information in the form of statements or summaries and asked to make judgements or supply comments on the items presented. Each round of the Delphi technique involves a response-analysis-feedback-response process.

There are four key features of the Delphi technique, including anonymity, iteration, controlled feedback and statistical aggregation of group responses ${ }^{29}$. Consensus occurs because the views of the participants converge through a process of informed decision-making ${ }^{30}$. The logic behind the Delphi method is partly statistical: that combined numerical estimates of participant's views would in general lead to more reliable estimates than those obtained from a single person ${ }^{27}$.

The advantage of the Delphi technique is that it is a relatively efficient and effective method of combining the expertise of a large group of geographically dispersed individuals to obtain information for planning and prediction purposes ${ }^{31}$. One of the major limitations of the method is when consensus amongst a panel is considered the 'correct' answer, because there is a danger of deriving collective ignorance rather than wisdom ${ }^{28}$. The effect of this limitation can be minimised by purposive sampling of genuine experts ${ }^{27}$ and matching results with observable events ${ }^{31}$. This study was modified from the traditional Delphi technique by using mostly structured, rather than open-ended questions, in response to information provided from a review of the issues embedded in the first questionnaire round.

\section{Literature review}

The provision of an initial review of available evidence for Delphi panellists is considered an important step in the consensus development process ${ }^{27}$. A literature review was undertaken by the author to search for published literature relating to training needs, competencies and workforce development in the fields of public health, nutrition and dietetics, health promotion, health education and public health nutrition, in order to isolate scholarship related to competencies. An Internet search was also conducted to identify non peer-reviewed government and organisational reports (grey literature) relevant to the search topics. Analysis of the literature that identified and listed competency units related to public health nutrition involved sorting and listing common or cross-cutting competencies, and competencies considered by the researcher to be relevant to public health nutrition. Fiftytwo competency units sorted into seven competency categories were identified for Round 1 testing (cf. Table 2, first two columns).

\section{Expert panel recruitment}

The sampling objective was to engage leaders in public health nutrition practice and/or education and training from various countries in the Delphi process. The sampling of a homogeneous group was purposive because the study aimed to define common ground and maximise areas of agreement. This approach is consistent with findings and recommendations from a systematic review of consensus development methods in health guideline development ${ }^{27}$. Invitations to participate in the Delphi group process were extended to a total of 37 public health nutrition experts in the European Union (EU), the USA and Australia. 


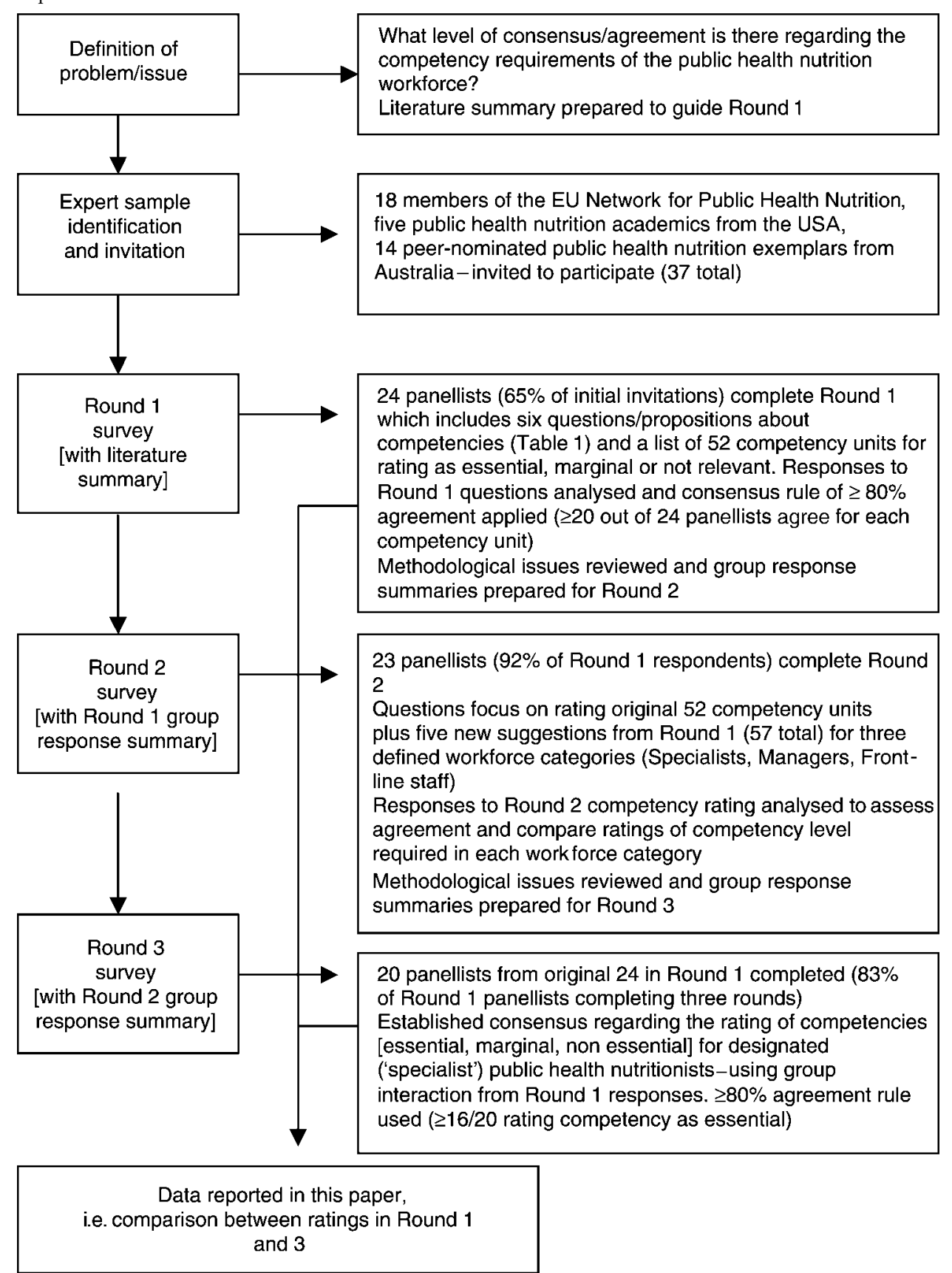

Fig. 1 Schematic of the Delphi process

EU experts were sampled from the existing European Network for Public Health Nutrition, which consists of academics and practitioners representing 17 EU countries/universities. Experts invited from the USA included five senior academic/practitioner public health nutritionists with an established scholarship publication record in public health workforce development. Fifteen of the most commonly nominated public health nutrition leaders from Australia, identified in an earlier qualitative consultation amongst advanced-level public health nutritionists conducted by the author ${ }^{32}$, were also invited to participate.

From this invitation process 24 public health nutrition experts from eight different countries in the EU, USA and
Australia $(\mathrm{EU}=9, \mathrm{USA}=5$, Australia $=10)$ agreed to participate as expert panellists. Twenty participated in all three rounds of the Delphi process. The panel composition was homogeneous and expert in the sense that panellists were public health nutrition leaders in practice, workforce development and/or education and training in their respective countries.

\section{Survey instruments}

Two different tools were developed and used in Rounds 1 and 3 in this study. The purpose of each tool is summarised in Table 1. 
Table 1 Summary of the structure and purpose of the Delphi questionnaires used in Rounds 1 and 3

\begin{tabular}{|c|c|c|}
\hline Round & Questionnaire structure & Purpose \\
\hline \multirow[t]{7}{*}{1} & $\begin{array}{l}\text { Questions embedded in a background literature summary. Six questions with } \\
5 \text {-point agreement scales for testing agreement with statements relating } \\
\text { to competencies }\end{array}$ & $\begin{array}{l}\text { To assess what level of consensus/agreement } \\
\text { there was regarding competency requirements } \\
\text { needed for effective public health nutrition action }\end{array}$ \\
\hline & $\begin{array}{l}\text { 1. There are many common or cross-cutting competencies } \\
\text { between public health and public health nutrition, but the difference } \\
\text { is that public health nutrition requires a competency mix specific } \\
\text { to nutrition and an understanding of nutrition issues }\end{array}$ & \\
\hline & $\begin{array}{l}\text { 2. Competencies need to reflect the mix of skills, } \\
\text { knowledge and attributes of the workforce or work group } \\
\text { rather than just focus on an individual professional group }\end{array}$ & \\
\hline & $\begin{array}{l}\text { 3. Competencies for a specialist tier (i.e. public health } \\
\text { nutritionists) are needed as a priority because this is the } \\
\text { workforce tier that is needed to facilitate and lead } \\
\text { public health nutrition action }\end{array}$ & \\
\hline & $\begin{array}{l}\text { 4. The development of a distinct professional group } \\
\text { (public health nutritionists) is important for increasing the capacity } \\
\text { to address public health nutrition issues }\end{array}$ & \\
\hline & $\begin{array}{l}\text { 5. Public health nutrition competencies can be developed } \\
\text { via numerous academic and experience pathways }\end{array}$ & \\
\hline & $\begin{array}{l}\text { Fifty-two competency units proposed from the literature review with } \\
\text { 3-point rating scales assessing competency units as essential, } \\
\text { marginal or not relevant }\end{array}$ & \\
\hline 3 & $\begin{array}{l}\text { Questions from Round } 1 \text { relating to rating competencies as } \\
\text { essential, marginal or not relevant repeated with group results } \\
\text { from Round } 1 \text { embedded. Essential competencies were defined } \\
\text { as competencies without which public health nutrition practice } \\
\text { effectiveness is limited. A further five competency units } \\
\text { suggested by panellists in Round } 1 \text { were added for rating by } \\
\text { panellists in the Round } 3 \text { survey. Panellists were directed to } \\
\text { rate competencies for designated public health nutritionists (an } \\
\text { individual with a minimum set of required competencies for } \\
\text { effective public health nutrition practice) }\end{array}$ & $\begin{array}{l}\text { To assess changes in consensus/agreement } \\
\text { level for competencies required } \\
\text { by specialist/designated public health } \\
\text { nutritionist workforce category }\end{array}$ \\
\hline
\end{tabular}

All questionnaires, associated literature and feedback summaries were forwarded to panellists by email. Responses were similarly returned to the researcher using this technology.

\section{Data analysis}

Responses to questions were entered into the Statistical Package for the Social Sciences, version 10.0 (SPSS Inc., Chicago, IL, USA) for storage and analysis. Comparison of responses from only the 20 panellists who completed all three survey rounds was made in order to eliminate the effect of attrition of extreme views on increasing consensus. Descriptive statistics were used to provide frequency of response distributions for data display and analysis, and to compare group response shifts between rounds (i.e. the change in the proportion of respondents rating a competency unit as essential). Assessment of agreement amongst expert panellists in this study was based on consensus cut-offs of $\geq 80 \%$ ( $\geq 16$ of 20 panellists) agreement that a competency was rated essential in Rounds 1 and 3. Stability of the consensus was considered to have been reached if the betweenround group response varied by $\leq 10 \%$, as applied in other studies ${ }^{30}$.

\section{Results}

From the initial sample frame $(n=37), 24$ experts agreed to participate in Round 1 (cf. Acknowledgements; representing a participation rate of $65 \%$ of initial invitees), 23 participated in Round 2 ( $92 \%$ of Round 1 participants) and 20 ( $83 \%$ of Round 1 participants) in Round 3. A cohort of 20 panellists completed all three rounds. All Delphi panel participants were senior academic or practising public health nutritionists in their respective countries.

\section{Agreement with propositions posed in Round 1}

Few respondents (3/24) disagreed that competencies needed to reflect the workforce or work group rather than individual practitioners. This was associated with many $(15 / 24)$ open-ended responses that reflected the need for multidisciplinary and intersectoral collaboration to address population-level nutrition problems. There was strong agreement (21/24) about the utility of internationally recognised professional standards for public health nutritionists and that the development of a distinct professional group (public health nutritionists) was important for increasing capacity to address public health nutrition issues (22/24). There was unanimous agreement that the development of these standards was a priority and 
Table 2 Public health nutrition competency ratings, Delphi survey Rounds 1 and 3 , with stability of agreement between rounds ( $n=20$ panellists)

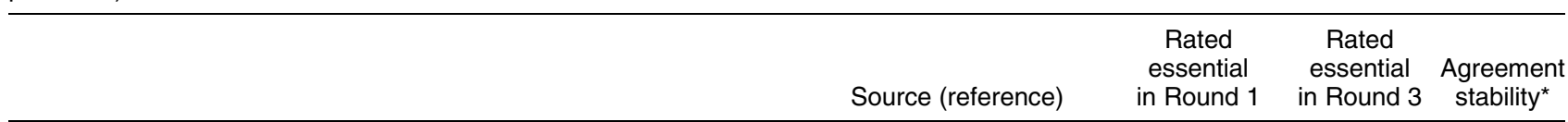

ANALYTICAL

Nutrition monitoring and surveillance

Assess the evidence and impact of health and healthcare interventions, programmes and services and apply these assessments to practice

Needs assessment - assessing population needs using various methods

Applied research, research and development - appraise, plan and manage research, interpret research findings and apply in practice

Analysing the determinants of nutrition issues using a

range of information sources

Food monitoring and surveillance

Scientific writing and dissemination of research

Improve the quality of health and healthcare services and

interventions through audit and evaluation

Health economics and economic evaluation applications

\section{SOCIO-CULTURAL AND POLITICAL}

Social sciences: knowledge and understanding of the psychological, social and cultural factors which influence food and dietary choices

Policy processes: policy development skills, influence policy development, evaluate policy impacts,

organisational politics

Community capacity building: community engagement, collaboration, partnership, coalition building and

community dimensions of practice skills

Advocacy - at government, organisation, profession levels

Cultural competency: awareness, knowledge and skills that

enable a system, agency or professional to work effectively in cross-cultural situations

\section{PUBLIC HEALTH SERVICES}

Intervention management: design, plan, implement, monitor and evaluate nutrition strategies and programmes for promoting health and well-being of the population, that reduce inequalities

Principles and practice of health education, health promotion theory, behaviour change and health promotion policy and programmes, public health methods

Knowledge of food and nutrition systems and community food needs

Provision of preventive nutrition programmes

Building capacity of the health workforce through training,

up-skilling and mentoring

Service and programme prioritisation based on identified

needs, their potential impact, as defined by objective

measurable criteria

Provide nutrition information/intelligence to various target

groups

Healthcare systems knowledge

Provision of clinical nutrition services

$3,17,21,23,32-34$

20

17,34

19

17

20

21,22

19

$3,17,21,23,25,33-37$

Proposed by author

Proposed by author Proposed by author

17, 21, 33, 35, 38

$3,25,33$

4

$21,23,25,32$

$17-19, \quad 23, \quad 25, \quad 32, \quad 33, \quad 17$

$39-42$

$3,17,18,21,32-34,38$,

42

$25,32,34,38,41$

18

$18,32,33,34,39$

$17-19,21-23,25,32-34$,

39,40

$21,23,32,39,43$

19

20

39

Proposed by author

19

19

$3,18,19,21,22,25,32-$

37-39, 41

Proposed by author

20

$3,21,32$

Grantsmanship - submission writing to access resources

to enable intervention and service delivery

Social marketing

$38,42,43$

22

Proposed by author

43 


\begin{tabular}{|c|c|c|c|c|}
\hline & Source (reference) & $\begin{array}{l}\text { Rated } \\
\text { essential } \\
\text { in Round } 1\end{array}$ & $\begin{array}{c}\text { Rated } \\
\text { essential } \\
\text { in Round } 3\end{array}$ & $\begin{array}{l}\text { Agreement } \\
\text { stability* }\end{array}$ \\
\hline \multicolumn{5}{|l|}{ MANAGEMENT AND LEADERSHIP } \\
\hline Strategic planning & 17,21 & 17 & 20 & \\
\hline Negotiation skills & 42 & 15 & 20 & \\
\hline Systems thinking skills & 25,42 & 14 & 20 & \\
\hline Team building & $21,32,42$ & 13 & 19 & \\
\hline $\begin{array}{l}\text { Computing and technology utilisation/information } \\
\text { technology }\end{array}$ & $19,21,32,34,38,43$ & 12 & 19 & \\
\hline $\begin{array}{l}\text { Leadership: motivation, dedication, vision } \\
\text { (personal attributes) }\end{array}$ & $25,33,34,38$ & 12 & 17 & \\
\hline $\begin{array}{l}\text { Örganisational behaviour, organisational management and } \\
\text { organisational change }\end{array}$ & $3,33,42$ & 10 & 15 & \\
\hline Personnel (staff) management & $3,21,32,42,43$ & 8 & 11 & \\
\hline Financial planning/management skills & $3,17-19,33-35,43$ & 9 & 9 & レ \\
\hline \multicolumn{5}{|l|}{ NUTRITION SCIENCE } \\
\hline $\begin{array}{l}\text { Assessment of food, nutrient and dietary intakes and } \\
\text { status in populations }\end{array}$ & $3,23,25,32,35,37-39,41$ & 19 & 20 & $\boldsymbol{V}$ \\
\hline Food composition & $3,23,25,32,35,37-39,41$ & 15 & 20 & \\
\hline Food guidance and goals & $3,23,25,32,35,37-39,41$ & 17 & 20 & \\
\hline Nutritional requirements & $3,23,25,32,35,37-39,41$ & 18 & 20 & レ \\
\hline Nutrition intervention strategy options and selection & $3,23,25,32,35,37-39,41$ & 18 & 20 & $\boldsymbol{\nu}$ \\
\hline Lifespan nutrition & $3,23,25,32,35,37-39,41$ & 16 & 20 & \\
\hline Physical activity assessment & Added after Round 1 & - & 12 & \\
\hline Food science & Proposed by author & 9 & 7 & $\boldsymbol{\nu}$ \\
\hline Dietetic management of disease & $21,37,44$ & 5 & 6 & $\boldsymbol{\nu}$ \\
\hline Physical fitness assessment & Added after Round 1 & - & 5 & \\
\hline $\begin{array}{l}\text { Assessment of food, nutrient and dietary intakes and status in } \\
\text { individuals }\end{array}$ & $3,23,25,32,35,37-39,41$ & 7 & 4 & \\
\hline \multicolumn{5}{|l|}{ PROFESSIONAL } \\
\hline Professional accountability and social responsibility & 41 & 19 & 20 & \\
\hline Ethics of public health nutrition practice & 33,41 & 19 & 20 & レ \\
\hline $\begin{array}{l}\text { Commitment to continual competency development and } \\
\text { lifelong learning }\end{array}$ & 33 & 18 & 20 & $\boldsymbol{V}$ \\
\hline $\begin{array}{l}\text { Able and willing to consult and refer to others when extra } \\
\text { competencies are required }\end{array}$ & Added after Round 1 & - & 20 & $\boldsymbol{V}$ \\
\hline Values and participates in peer review & Added after Round 1 & 16 & 19 & \\
\hline Reflective practice to enhance performance & 35 & 17 & 19 & $\boldsymbol{\nu}$ \\
\hline $\begin{array}{l}\text { Knowledge of the roles and cultures of other health } \\
\text { professions in public health }\end{array}$ & Added after Round 1 & - & 17 & \\
\hline
\end{tabular}

* Stability of agreement refers to $\leq 10 \%$ variation in the number of panellists reporting the competency unit as essential between Round 1 and Round 3 . Bold text represents competency units with agreement reaching the Round 3 consensus criterion of $\geq 16 / 20(\geq 80 \%)$ in agreement.

that the competencies for public health nutrition share many of those required for public health generally, but with additional competency specific to nutrition. Most agreed (20/24 agreed or strongly agreed, four disagreed) with the proposition that public health nutrition competencies can be developed via numerous pathways; however, openended responses $(6 / 24)$ suggested in practice that training in nutrition was a preferred prerequisite.

Table 2 identifies competency units collated from the international literature that were proposed and tested in the Delphi surveys, and the results from rating of competency units by the 20 panellists who completed Rounds 1 and 3. Very few of the competency units listed in Round 1 were rated non-essential by the panel of experts. Those that were tended to be related to clinical service provision $(8 / 20)$, including dietary counselling (7/20) and assessment of food/nutrient intakes and status of individuals $(4 / 20)$. These ratings did not vary by more than 10\% between Rounds 1 and 3 .

Comparison of the proportion of responses between Round 1 and Round 3 among the 20 panellists who completed both these rounds showed stability of agreement (between-round variation of $\leq 10 \%$ in group response) for 25 of the original 52 competency units. Competency units listed in Table 2 in bold type represent those rated as essential at the consensus criterion of $\geq 80 \%$ agreement after Round 3. The most obvious strengthening of agreement between rounds about the essential nature of competencies was in the competency category of management and leadership. 
Twenty-six of the Round 1 competency units listed ( $n=52$ ) were rated as essential by $\geq 80 \%$ of panellists and this number increased to 39 of the original listing rated as essential at this consensus level after Round 3. Of the five additional competency units inserted for testing in Round 3, two (able to consult and refer to others when extra competencies are required and knowledge of the roles and cultures of other health professions in public health) were rated as essential at the consensus level. There was considerable variability in the ratings of the five competencies added after Round 1, which were related to physical activity assessment (12/20 essential, 7/20 marginal, 1/20 not relevant), physical fitness assessment (5/20 essential, 7/20 marginal, 8/20 not relevant) and the ability to speak more than one language $(7 / 20$ essential, 10/20 marginal, 3/20 not relevant).

\section{Discussion}

\section{Study limitations}

The size and composition of the expert panel in this study may limit the generalisability of the results obtained. The panellists in this survey were characterised by their leadership status in public health nutrition at national and international level and all were active scholars, practitioners and/or educators in the field of public health nutrition. As a result, the opinions expressed through this survey process are worth noting, but may not necessarily represent the opinions of other public health nutrition experts in countries not represented, such as countries with developing economies.

Whilst reliability has been shown to be maximised with panel size in excess of 12 experts, little is known about how expert panel representativeness affects results in consensus development techniques ${ }^{27}$. It is possible that increasing the expert panel size or the inclusion of public health nutrition experts from other countries or from other related fields such as epidemiology may have altered the level of agreement obtained. Similarly, a greater proportional representation of panellists from the USA may have produced different levels of agreement. Whilst this study demonstrates a good level of agreement amongst public health nutrition experts in this sample, further testing of this competency set amongst a broader sample of public health nutrition and other experts is required before it can be generalised internationally.

There is no agreed standard as to how to measure consensus $^{29}$. Empirically, consensus is determined by measuring variance in the responses of Delphi panellists over rounds, with a reduction in variance taken to indicate that greater consensus has been achieved ${ }^{29}$. Other methods have been used, including counting betweenround group response shifts of $\leq 10 \%$ as indicating stability of agreement (consensus) ${ }^{30}$. The use of the arbitrary agreement response cut-off of $\geq 80 \%$ of panellists as representing consensus in this study requires scrutiny.
Increasing the cut-off to $\geq 90 \%$ representing consensus would have resulted in five fewer competencies being rated as essential at consensus proportions (36 vs. 41). Irrespective of which cut-off is applied, the large number of competency units rated by all panellists as essential $(n=21)$ indicates a high degree of agreement amongst panellists, with the competency units being identified in earlier scholarship and through suggestions offered during this study.

\section{Competencies}

The high level of agreement with the competency propositions posed in Round 1 of the Delphi process is not surprising given the homogeneous nature of the expert panel, being all actively involved in the training and development of the public health nutrition workforce in their respective countries.

Competencies have traditionally been developed for a particular professional or work group to act as standards for workforce development (training, performance review, recruitment and continuing professional development). One of the conceptual difficulties with assessing the importance of competencies relevant to public health nutrition relates to the question 'Are we referring to an individual practitioner or the broader workforce or work group?' This difference is important because of the differences in jurisdiction and level of influence and practice that individual practitioners may operate in, which may influence competency needs and applications. An earlier consultative study amongst the Australian public health nutrition leadership group reported a widely held view that there is a set of core competencies relevant to public health nutrition practice in all contexts, but that these will be differentially applied depending on work context $^{32}$. Results from this study appear to support the concept of core competencies (those that are applicable across jurisdictions and in different contexts) and that many of these are similar to those of generic public health practice as outlined both in the USA ${ }^{18}$ and Australia ${ }^{44}$.

The large number of different competency units identified and rated as essential for effective public health nutrition practice reflects the breadth of skills, knowledge and applications required to address the often complicated problems encountered in public health nutrition practice. These findings suggest that it may be unrealistic to expect an individual practitioner to have proficiency in all the competency units identified, emphasising the need to develop work teams that ensure the competency mix required for effective work effort. This view is consistent with earlier views about the need for interdisciplinary approaches to public nutrition ${ }^{24,25}$ and the multidisciplinary composition of public health nutrition workforces ${ }^{32}$.

Competency units relating to the provision of directcare nutrition and dietetic services were consistently rated as marginal or not relevant to public health nutrition practice, reinforcing earlier views that it is important to 
delineate public health nutrition from clinical prac-

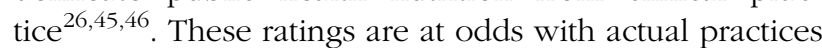
in countries such as Australia ${ }^{47}$ and the USA ${ }^{48}$, where the public health nutrition workforce currently provides various levels of direct-care services. These ratings may also reflect the recognition amongst the expert panel that limited-reach approaches using a limited range of strategies may not effectively address public health nutrition problems.

The lack of agreement about the importance of competencies relating to physical activity promotion and assessment amongst this expert panel is interesting, given the increasing recognition of the synergies between nutrition and physical activity within the field of public health nutrition. It does, however, follow results from the first round of this process, which demonstrated a lack of consensus about including physical activity within definitions of public health nutrition ${ }^{26}$.

The high level of agreement about essential competencies amongst the international panel seems to support the initial premise that there is a set of core competencies that are transferable across countries, at least in countries with developed economies. Given the lack of input from experts from countries with developing economies, this premise requires further testing in this context.

The high level of agreement on competency units considered essential for effective public health nutrition practice identified and tested in this process provides a basis for the development of internationally transferable competency standards for public health nutrition, as a distinct field of practice. Given some of the limitations of the competencies approach and the evolving nature of public health nutrition work needs, it is important to recognise that competencies need to be dynamic and change in response to changes in the field.

\section{Acknowledgements}

This study is a product of the International Consensus on Public Health Nutrition Competencies Project conducted by the author in collaboration with the Unit of Preventive Nutrition, Karolinska Institutet. The assistance provided by Agneta Yngve and Betsy Haughton in identifying experts in Europe and the USA is appreciated. The contributions and generous support of the following 20 experts (country identified in brackets) from the expert panel who completed all three survey rounds are acknowledged: Agneta Yngve (Sweden), Jackie Landman (UK), Barrie Margetts (UK), Felix Gutzwiller (Switzerland), Irja Haapala (Finland), Maria Daniel vaz de Almeida (Portugal), Carmen Perez Rodrigo (Spain), Janice Dodds (USA), Alice Linehan (USA), Mary Story (USA), Betsy Haughton (USA), Ian Darnton-Hill (USA), Boyd Swinburn (Australia), Lauren Williams (Australia), Mark Lawrence (Australia), Marg Miller (Australia), Cate Burns (Australia), Julie Woods
(Australia) and Karen Campbell (Australia). One of the expert group from Europe elected to remain anonymous.

\section{References}

1 McAllister M. Competency standards: clarifying the issues. Contemporary Nurse 1998; 7: 131-7.

2 Dodds J, Kaufman M, eds. Personnel in Public Health Nutrition for the 1990's: A Comprehensive Guide. Washington, DC: The Public Health Foundation, 1991.

3 Dodds J, Polhamus B. Self-perceived competence in advanced public health nutritionists in the United States. Journal of the American Dietetic Association 1999; 99 808-12.

4 Landman J, Buttriss J, Margetts B. Curriculum design for professional development in public health nutrition in Britain. Public Health Nutrition 1998; 1: 69-74.

5 Landman J. Training in Public Health Nutrition: symposium at the 17th International Congress of Nutrition, Vienna. Public Health Nutrition 2001; 4: 1301-2.

6 Bowden J, Masters G. Implications for Higher Education of a Competency Based Approach to Education and Training. Canberra: Australian Government Publishing Service, 1993.

7 Chapman H. Some important limitations of competencybased education with respect to nurse education: an Australian perspective. Nurse Education Today 1999; 19: 129-35.

8 Hager P. Is there a cogent philosophical argument against competency standards? Australian Journal of Education 1994; 38: 3-18.

9 Gonzi A. Competency based assessment in the professions in Australia. Assessment in Education 1994; 1: 27-44.

10 Hager P, Gonzi A. Competency based standards: a boon for continuing professional education. Studies in Continuing Education 1991; 13: 24-40.

11 Rivers K, Aggleton P, Whitty G. Professional preparation and development for health promotion: a review of the literature. Health Education Journal 1998; 57: 254-62.

12 Centers for Disease Control and Prevention/Agency for Toxic Substances and Disease Registry. Strategic Plan for Public Health Workforce Development. Toward a Life-long Learning System for Public Health Practitioners. Washington, DC: US Department of Health and Human Services, 2001.

13 Kennedy V, Moore F. A systems approach to public health workforce development. Journal of Public Health Management and Practice 2001; 7: 17-22.

14 Riddout L, Gadiel D, Cook K, Wise M. Planning Framework for the Public Health Workforce: Discussion Paper. Melbourne: National Public Health Partnership, 2002.

15 Gebbie K, Rosenstock L, Hernendez L. Who will Keep the Public Healthy? Educating Public Health Professionals for the 21st Century. Washington, DC: Institute of Medicine/ National Academic Press, 2002.

16 Lichtveld M, Cioffi J, Baker E, Bailey S, Gebbie K, Henderson $\mathrm{J}$, et al. Partnership for front-line success: a call for a national action agenda on workforce development. Journal of Public Health Management and Practice 2001; 7: 1-7.

17 Healthwork UK. National Standards for Specialist Practice in Public Health: An Overview (Approved Version). London: Healthwork UK, 2002.

18 Council on Linkages between Academia and Public Health Practice. Core Competencies for Public Health Professionals. Washington, DC: US Department of Health and Human Services, 2002.

19 Lane D, Ross V, Chen D, O'Neill C. Core competencies for Preventative Medicine residents: version 2. American Journal of Preventative Medicine 1999; 16: 367-72. 
20 Precision Consultancy. Draft Health Promotion Competency Standards. Melbourne: Precision Consultancy, 2000.

21 Howat P, Maycock B, Jackson L, Lower T, Cross D, Collins J, et al. Development of competency-based university health promotion courses. Promotion E Education 2000; 7: 33-8.

22 National Commission for Health Education Credentialing, Inc. (NCHEC). Responsibilities and Competencies for Health Educators. Allentown, PA: NCHEC, 2002.

23 Nutrition Society. How to Specify Levels of Learning Outcome in Public Health Nutrition; Annex. London: Nutrition Society, 2000.

24 Pelletier D. Advanced training in food and nutrition: disciplinary, interdisciplinary, and problem orientated approaches. Food and Nutrition Bulletin 1997; 18: 134-45.

25 Rogers B, Schlossman N. 'Public nutrition': the need for cross-disciplinary breadth in the education of applied nutrition professionals. Food and Nutrition Bulletin 1997; 18: $120-33$.

26 Hughes R. Definitions for public health nutrition: a developing consensus. Public Health Nutrition 2003; 6: 615-20.

27 Murphy M, Black N, Lamping D, McKee C, Sanderson C, Askham J, et al. Consensus development methods, and their use in clinical guideline development. Health Technology Assessment 1998; 2: i-iv, 1-88.

28 Jones J, Hunter D. Qualitative research: consensus methods for medical and health services research. British Medical Journal 1995; 311: 376-80.

29 Rowe G, Wright G. The Delphi technique as a forecasting tool: issues and analysis. International Journal of Forecasting 1999; 15: 353-75.

30 Duffield C. The Delphi technique: a comparison of results obtained using two expert panels. International Journal of Nursing Studies 1993; 30: 227-37.

31 Polit D, Hungler B. Nursing Research: Principles and Methods, 6th ed. Philadelphia, PA: Lippincott, 1999.

32 Hughes R. Public health nutrition workforce composition, core functions, competencies and capacity: perspectives of advanced-level practitioners in Australia. Public Health Nutrition 2003; 6: 607-13.

33 Health Care Alliance. Health Training Package: Population Health Scoping Report - Draft. Sydney: Community Services and Health Training Australia, Inc., 2003.

34 Allegrante J, Moon R, Auld E, Gebbie K. Continuingeducation needs of the currently employed public health education workforce. American Journal of Public Health 2001; 91: 1230-4.

35 American Dietetic Association (ADA). Standards for
Professional Practice for Dietetics Professionals. Chicago, IL: ADA, 1997.

36 Phillips S, Ash A, Tapsell L. Dietitians' views on the current competency standards for entry-level dietitians. Australian Journal of Nutrition and Dietetics 2000; 57: 190-7.

37 Phillips S, Ash A, Tapsell L. Relevance of the competency standards to entry-level dietetic practice. Australian Journal of Nutrition and Dietetics 2000; 57: 198-207.

38 Pew Health Professions Commission. Recreating Health Professional Practice for a New Century: Fourth Report of the Pew Health Professions Commission. San Francisco, CA: Pew Health Professions Commission, 1998.

39 Olmstead-Schafer M, Story M, Haughton B. Future training needs in public health nutrition: results of a national Delphi survey. Journal of the American Dietetic Association 1996; 96: $282-3$.

40 Hughes R. The experience of dietitians working on interventions in the takeaway food sector: lessons for workforce development. Australian Journal of Nutrition and Dietetics 2002; 60: 38-41.

41 Association of Teachers of Maternal and Child Health (ATMCH). Maternal and Child Health Competencies. Washington, DC: ATMCH, 2001.

42 Wright K, Rowitz L, Merkle A, Reid W, Robinson G, Herzog $\mathrm{B}$, Weber D, et al. Competency development in public health leadership. American Journal of Public Health 2000; 90: 1202-7.

43 Hunt A, Hilgenkamp K, Farley R. Skills and competencies of dietitians practising in wellness settings. Journal of the American Dietetic Association 2000; 100: 1537-9.

44 National Public Health Partnership (NPHP). Public Health Practice in Australia Today - Core Functions. Melbourne: NPHP, 2001.

45 Hughes R, Somerset S. Definitions and conceptual frameworks for public health and community nutrition: a discussion paper. Australian Journal of Nutrition and Dietetics 1997; 54: 40-5.

46 Food and Nutrition Special Interest Group. Strategic Plan of the Food and Nutrition SIG of the Public Health Association of Australia. 2001. Canberra: Public Health Association of Australia, 2001

47 Hughes R. Work practices of the community and public health nutrition workforce in Australia. Nutrition \& Dietetics 2003; in press.

48 Haughton B, Costello C, Traylor M, Reeves K. Public health nutrition practices to prevent low birth weight in eight southeastern states. Journal of the American Dietetic Association 1992; 92: 187-92. 